\section{Skill and Expertise in Perception*}

Susanna Siegel

Forthcoming in Routledge Handbook of Skill and Expertise,

Edited by Ellen Fridland and Carlotta Pavese.

We can distinguish theses that connect skill with perception in general from theses that connect skill with perceptual experience in particular. Perceptual experiences are the conscious states and episodes that are characteristic of perception. These experiences are sensitive to how one's attention is distributed. One can undergo perceptual experiences both in cases when the experience leads to knowledge, or in hallucination or illusion. By contrast, perception in general includes both perceptual experiences and the unconscious information processes that give rise to them via the perceptual system. So there is more to perception than perceptual experience. The focus of this entry is the relationship of skills to perceptual experience.

How are perceptual experiences related to skills? According to some researchers, skills can be exercised only in intentional actions. But when discussing the relationship between skills and perceptual experience, it's useful to work with a broader notion of skill that could count as skilled behavior the exercise of some recognitional abilities that don't involve intentional action, such visually recognizing avocadoes, or your favorite sheep in the flock, or the sound of A-flat, without antecedently intending to do any of these things. The broader notion of skill includes these forms of expertise.

It's clear that perceptual experience plays a central role in skilled behavior of all kinds. It is difficult (if not impossible) to catch a football if you can't see or otherwise feel it coming, or to play chess while blindfolded, or to recognize your favorite sheep without getting any sensory input. At a minimum, perceptual experience enables these forms of skilled action. Some philosophers go farther and suggest that perceptual experience is itself a kind of skilled action, or that it constitutively involves skilled actions of various kinds. Whether or not any version of this furthe claim is true, there are several important ways in which perceptual experiences might be thought to manifest a subject's skills. This entry focuses on three of them. Section 1 discusses the idea that perceptual experience consists in motor skills. Second 2 focuses on the idea that perceptual experience can consist partly in skilled mental actions of recognition, such as recognizing a particular animal scurrying past as a mouse. Section 3 reviews some of the main ways that various kinds of expertise or cultural understanding manifest themselves in patterns of perceptual attention.

"Thanks to Kevin Connolly, Kati Farkas, Ellen Fridland, Zoe Jenkin, Samantha Matherne, Matthew McGrath Jessie Munton, and Carlotta Pavese for criticism and discussion.
1. Are motor skills constitutive of perceptual experience?

The $20^{\text {th }}$ century French phenomenologist Maurice Merleau-Ponty analyzed perceptual experience as necessarily engaging motor skills. In Merleau-Ponty's paradigmatic cases of perception, the flow of information taken in by perceivers is inseparable from the way they move through a scene. On this view, even superficially static perceptions engage motor skills, such as seeing the color of a table as uniform when different parts of it are differently illuminated. By an a table as the han' movements are unified in their intake of kinesthetic tactile, a dance, the dancers' movements are unified in their intake of kinesthetic, tactile, visual and auditory information to such an extent that any purely sensory dimensions of the dancing process would be hard to factor out from motor
dimensions. Merleau-Ponty's focus on roles of the body in perceptual experience has dimensions. Merleau-Ponty's focus on roles of the body in perceptual expe inspired some contemporary thinkers to construe the sensory and motor dimensions of perceptual experience as best und
dancing (Hurley 1998, Kelly 1999, Noë 2005).

How far could this model plausibly generalize? Watching a sunset or examining th colors of paint are other paradigms of perception, but they apparently need not involve doing much with one's body. Because one is just looking, these experience are more like taking in a spectacle than actively creating one. Some followers of Merleau-Ponty try to make the case that even color perception involves the bodily activity of finding what Merleau-Ponty called the optimal point of view from which the color - or anything - should be viewed. ${ }^{1}$ According to these interpreters, we gravitate toward optimal viewpoints, and finding these optima is a skill on par with knowing how to walk: it is a learned skill that we are innately disposed to develop.

What kind of evidence could support the idea that we are sensitive to visual optima? The main evidence would seem to be behavioral dispositions to gravitate toward optimal viewpoints and feel uncomfortable with suboptimal ones. But if perceptual experience in general consists in exercising the skill of finding optimum viewpoints, and if different qualities (color, shape, motion and so on) each have their own optimum, then we will often have competing dispositions. And if that's our situation, or if for all we know it is our situation, then we cannot straightforwardly take the behavior we find in others, or the discomfort we feel in ourselves, to be the manifestation of dispositions to move toward the optimum. There is no obvious feedback that indicates which behavior meets the optima. And if there are neithe phenomenological nor behavioral markers of such optima, for many forms of perception there are no obvious success conditions for perceiving optimally. So even if Dreyfus and Kelly's approach captures an aspect of some perceptual experiences when they are deeply integrated with bodily action, the analysis of these aspects may not support the broader idea that perceptual experience is constitutively an exercise of skilled bodily action. Here's a case where skills are construed as manifesting in dispositions to navigate the social and physical environment in a way that others would be legible to others in that environment, rather than as an intentional action.

${ }^{1}$ S. Kelly 1999, 2005, H. Dreyfus 2002, 2005 
Dreyfus and Kelly focus on the optimal viewpoints in analyzing Merleau-Ponty's idea of the intentional arc. In developing this idea, Merleau-Ponty brings into focus a whole range of mental states that situate us in social and physical environments. As he puts it the intentional arc is that set of representations by which we "project around us our past, our future, our human milieu, our physical situation, our ideological situation situated within all of these relationships".2

Merleau-Ponty construes the intentional arc as an embodied mode of intentionality. According to him, our motor dispositions embody a kind of understanding of the things we perceive (perhaps optima would be but one example). For example, in the social realm, the culturally specific boundaries of personal space regulate how close we stand to one another, and how far we can squish together on a subway withou feeling that boundaries have been violated (Kelly 2005). Our bodily stances also communicate cues of social status and relationships, such as authority, deference, and confidence. Exhibiting and interpreting these cues is a form of cultural literacy, expressed through the body, and it constitutively engages perceptual experience.

On this analysis, perceptual experience constitutively includes skills of navigating the social and physical environment, rather than being a representation that mediates between sub-personal perceptual inputs and behavioral outputs, in conjunction with other beliefs, desires and preferences. The unit of analysis here is something that both has a phenomenological feel and consists in a set of dispositions to respond to cultural and physical environments in culturally recognizable ways ${ }^{3}$

If Merleau-Ponty is correct, then cultural literacy is mediated by attention, including joint attention. This prediction of Merleau-Ponty's is independently plausible. Like other primates, humans follow the gaze of their con-specifics to direct their attention across all sorts of scenarios. ${ }^{4}$ Gaze-following is part of joint attention, in which person $A$ attends can tell by perception what person $B$ is attending to, an person A goes on to attend to it as well. In this way, person B's attention directs person A's attention. Joint attention is a fundamentally social form of perception and it provides a basis for human cooperation. Just think of how your attention has to be coordinated with another person's, if you are going to carry a table down a flight of stairs, or pass each other a narrow path, or carry on a conversation. Actors in cooperative human activities typically have to presume that they can direct their cooperants' attention to the relevant part of the flow of information. For these reasons, joint attention is part of the basis on which Merleau-Ponty's intentional arc could unfold.

${ }^{2}$ Merleau-Ponty (PhP) 137. For further analysis, see Matherne (2017) on MerleauPonty's notion of style.

${ }^{3}$ Noe and O'Regan (2001)

${ }^{4}$ Eilan et al. (2015)
Independently of the picture inspired by Merleau-Ponty on which perceptual experience is infused with motor skills, we can also zoom in on more piecemeal recognitional abilities and consider their relationships to perceptual experience. This brings us to the idea that perceptual experience could be constituted wholly or Us to the id a that perceptual experince could be constituted wholly or in part by exercisi

2. Are recognitional dispositions ever constitutive of perceptual experience?
Chances are good that you can recognize avocados by sight, or your housemate's footsteps on the stairs by the patterns of sound, or coffee brewing by its smell. What kind of knowledge do you have, when you know what avocados look like, or when you know what someone's footsteps sound like, or what coffee smells like?

A first possibility is that you have some articulable knowledge detailing the feature by which you can recognize avocados. Even if you had never seen avocados before, someone could describe them to you, and you could learn from them that avocados are oval, and than depending on the variety they have either blackish thick skin with knobby texture, or greenish thin skin that's relatively smooth. In this way, you could know this is what avocados look like, even if you had never actually seen one.

A second possibility is that your knowledge of what things look like could consis ultimately in an ability to recognize them (as per Lewis 1990). For instance, if housemate Jack has a bad knee, it might give his gait a distinctive rhythm that you can recognize when you hear it. A rhythmic sophisticate might know that the interval in between the sound of the left foot stepping and the sounds of the right foot landing is on the sound the left foot stepping and the sounds of the right foot landing is one-and-a-half times longer than the interval between right foot stepping and left foot landing, and might be able to describe the sound of Jack's
steps to you even if neither of you had ever heard any gait like that. But let's steps to you even if neither of you had ever heard any gait like that. But let's
suppose that you're not a rhythmic sophisticate, and that no one has ever describe suppose that you're not a rhythmic sophisticate, and that no one has ever described
anyone's gait to you before. You still might simply know how to identify Jack on the anyone's gait to you before. You still might simply know how to identify jack on the
basis of the sound of his footsteps. Your knowledge would consist in an ability to basis of the sound of his footsteps. Your knowledge would consist in an ability to recognize Jack. If you

Let's focus on this second option, and call it the purely practical one. ${ }^{5}$ Is perceptua experience then constituted either by acquiring or by exercising such abilities? If so, then that may be because perceptual experience is partly constituted by having these abilities, in which case we have an example of the thesis that perceptual experience is constituted by a type of mental action.

5 Matherne (2014) argues that this position is found in Kant. Pavese (2015) defends a mixed view. For useful discussion of perceptual recognition in general, see Brewer (2011), McGrath (2017) and Millar (2019). 
Alternatively, what if perceptual experience is purely an occasion for exercising recognitional abilities? Sometimes we have a concept, such as rose, and we have the disposition to recognize roses, but we fail to apply the concept to a rose we encounter. Kant described this type of situation when discussing a physician who sometimes makes errors of judgment. ${ }^{6}$ If this situation can arise with every concept we have, then recognition and perceptual experience are only contingently connected.

This type of contingency can occur in different strengths. Its strongest form allows that perceptual experience never constitutively involves the application of any recognitional dispositions at all. In that case, perceptual experiences enables recognition of things, but is not constituted by recognitional abilities, even in part. In a weaker form, in every perceptual experience, some recognitional dispositions are exercised, but no recognitional disposition that is guaranteed to be exercised on every occasion on which it would be fitting to do so. This weak form reintroduces a type of constitutive link between perceptual experiences and recognitional dispositions.

Just as we can ask how perceptual experience relates to practical ability to recognize things like roses, we can ask a parallel question about the relationship between perceptual experiences and introspection. When you know what it's like to see red, you know something about the character of a type of visual experience. In Frank Jackson's thought experiment, a neuroscientist Mary who is said to know all the physical facts sees red for the first time after living in a black and white room. What does Mary come to know, when she learns what it's like to see red? According to some philosophers, knowing what it's like to see red is ultimately a kind of abily wh it's like to have this type of color experience is an irreducibly practical ability.

\section{How can perceptual attention reflect the subject's skill?}

There are many ways in which specialized expertise including modes of being culturally embedded can manifest itself in patterns of attention.

${ }^{6}$ Kant imagines a physician, judge or statesman who "can have many fine pathological, juridical, or political rules in his head, of which he can even be a thorough teacher, and yet can easily stumble in their application, either because he is lacking in the natural power of judgment (though not in understanding), and to be sure understands the universal in abstracto but cannot distinguish whether a case in concreto belongs under it, or also because he has not received adequate training for this judgment through exples and actual business" KrV A134/B173. Matherne (2014) discusses this example in connection with perceptual experience.

${ }^{7}$ Lewis $(1990)$
When you perceive a scene, your attention is always distributed in a way that puts some things into the foreground and other thing into the periphery. How your attention is distributed can depend on other factors as well, including whether the scene contains the types of stimuli that "grab" your attention, such as a sudden movements, bright flashes, loud bangs, or unexpected behavior.

It can also depend on what you're already in the midst of doing, and on how well you know how to do it. For instance, a softball player at the bat knows where to look to figure out what kind of pitch is coming and how best to hit it. A pickpocket observing a potential victim knows which gestures indicate where the victim keeps his wallet, and whether he is sufficiently distracted not to notice a hand reaching in to take it out. Someone lacking expertise in thievery who is watching the very same man could easily have no idea where his wallet is, let alone how to snatch it.

Distributions of attention can also depend on scientific expertise. Faced with the same sequence of $x$-ray images, a radiologist and a novice will parse each image differently. To the radiologist, some patterns of lines and light contrast stand out from others, whereas the novice finds no difference in kind between them. The radiologist's expertise allows her to find the tumors in the image. She knows what to look for, and she knows when she has found it. And moving down a continuum from scientific expertise to expertise gained merely by exposure, someone used to seeing toads is better than someone with less exposure to at finding a toad camouflaged on a tree.

The $18^{\text {th }}$-century Scottish philosopher Thomas Reid observed that patterns of exposure to things could lead perceivers to differentiate between properties that previously were indistinguishable to them. For example, a wine ignoramus may taste no dif them apart. A birder can see the visible differences between two kinds of ducks, whereas a duck novice can't tell them apart. ${ }^{9}$ Pairs of phonemes that sound differe to speakers of a language sound the same to people who don't understand that language. In these ways, expertise can improve perceptual acuity.

Expertise in birds, wine, and language improves the overall epistemic position of the experts in these examples. But in other contexts, selective improvement in acuity introduces perceptual asymmetries that highlight epistemic limitations. The prime example is facial differentiation. In racially segregated parts of the United States, the most lengthy and socially valued interactions occur primarily among people who share a socially designated 'race'. People who are designated regularly as belonging a racial category, such as white, and who interact mainly with the same are much better at visually discriminating between different white faces, and much worse at

${ }^{8}$ This observation about toads is an instance of the general claim that being used to seeing F's gives you a facility at perceptually distinguishing F's from their seeing F's gives you a facility at perceptually distinguishing Fs from the

${ }^{9}$ Pylyshyn, Z. 1999, Goldstone (2015), Connolly (2019). 
visually discriminating between faces of people belonging to other races. ${ }^{10}$ This pattern of interaction has an adverse effect on the ability to discriminate between faces of the people belonging to the socially designated "races" with whom they do not interact

When new abilities to differentiate within a category (such as faces, wines, or birds) emerge from a long pattern of exposure to instances of that category, the process is known as perceptual learning. ${ }^{11}$ Perceptual learning differs from perceptual development, which is a matter of brain maturation. Even the most mature development, which is a matter of brain maturation. Eve

When a perceiver's acuity within a category increases due to perceptual learning, her perceptual experiences reflect both her ability to differentiate and her past pattern of exposure to instances of the category.

Perceptual learning is most often illustrated by improved acuity in categorization But the general idea that long-term changes in acuity can result from practice and experience applies to perception of structures as well. Gaining practice and expertise in music, for example, can improve the ability to find the beat in a piece of music and keep track of it. A beat is the temporal structure of a piece of music. It may or may not have an audible expression (for instance in the pattern of sounds made by a drumbeat). A long-term change in sensitivity to this kind of temporal structure due to patterns of exposure or practice trying to find the beat belongs to the same family of perceptual influences as improvements in acuity within a category. ${ }^{12}$

Aside from categorization and differentiation, perceptual learning in an extended sense can take the form of social facility in a culture. In any human interaction among adults, some possibilities of interaction are foregrounded and others are backgrounded, and normally it is commonly known what the main options are for how the situation is likely to unfold. For instance, it is possible to learn the social how the situation is likely to unfold. For instance, it is possible to learn the social
cues that someone wants to shake your hand, catch your eye, talk to you, or avoid cues that someone wants to shake your hand, catch your eye, talk to you, or avoid
you, and these possibilities of interactions are learned and can be culturally specific.

Another way for cultural embeddings to shape perceptual experience brings us back to joint attention. Alongside its role in social coordination, joint attention is also a means by which people develop sensitivity of social value. Adams and Kveraga (2015) present experimental evidence that in the United States, the extent of gaze-

${ }^{10} \mathrm{This}$ effect is known as the cross-race effect. For an overview see Meissner, C.A et al (2001).

${ }^{11}$ Goldstone (2015), Connolly (2017) [sep]

12 On rhythm perception, see Boll-Avetisyan, $\mathrm{N}$ et al (2017). following behavior is sometimes sensitive to race and social power. To a statistically significant degree, Americans of European descent (white participants) followed the gaze of white faces but did not follow the gaze of Americans of African descent (black participants), whereas black participants followed the gaze of both groups of faces. To the extent that gaze-following indicates confidence that the followedperson's object of attention, or experience of it, is epistemically valuable, it is reasonable to hypothesize that this result reflects an underlying pattern of socia valuation, and specifically the epistemic under-valuation of black adults by white adults.

Merleau-Ponty would predict that a person's cultural embedding can affect distributions of attention, and this prediction too is borne out. Eberhardt (2003) found that the cultural stereotype that associates black men and crime becomes 'visual tuning device' that directs attention in toward stereotype-congruent information, and away from stereotype-incongruent information. ${ }^{13}$ For instance, in one experimental paradigm, participants were primed with the face of a man and then shown a series of image that gradually morphed into a clear image from a noisy one. Participants find crime-related objects such as guns and knives at a lower threshold after seeing the face of a man who is black, compared to the threshold at which they report such objects after seeing the face of a man who is white. And when the primed face is black, participants find crime-related objects at a lower threshold than they find non-crime related objects such as watches or bugles.

In another experimental paradigm involving a 'dot-probe' task, participants are first quickly shown a subliminal crime-related prime, such as a picture of a gun, fingerprint, police badge, or handcuff. The image is flashed too quickly for them to report what they see. They are then shown two male faces one black and them to report what they see. They are then shown wo male faces, one black and one white and after the With a crime prime participants find the dot more quickly when it was shown. With a crime prime, participants find the dot more quickly when replaces black male face, compared to when it replaces a white male face, and compared to when there is no prime at all. Eberhardt takes this experiment to show that crime prime directs attention to black male faces. Here, culturally entrenched stereotypes produce associations that in turn facilitate patterns of attention that reflect those stereotypes.

Finally, both ethical and aesthetic engagement can take the form of patterns of attention as well, and in these ways, perceptual skills are central to both ethics and aesthetics. Consider a long and complicated piece of classical music. Musically engaged people can direct their attention to structures within the music, distinguishing a theme from its development, and finding other aesthetically relevant features of the music. When attention is distributed this way, the musically important features of the symphony are made salient (a point emphasized by Nanay 2015). In ethics, as philosopher and novelist Iris Murdoch emphasized, in some cases, acting well consists in part in noticing the good-making or bad-making

${ }^{13}$ For some criticisms of statistical analysis in Eberhardt's study, see Francis 2016. 
features of a scene, or the features that call for specific kinds of moral action, such as giving up one's seat on a bus for someone who needs it more badly. One could see these dispositions as a kind of moral skill in the form of perception, an idea developed at length in a quite different ways by Bengson et al (forthcoming), Fridland 2017, Mandelbaum 1955, and Murdoch 1967.14

\section{Bibliography}

Adams, R. and K. Kveraga 2015. Social Vision: Functional Forecasting and the Integration of Compound Social Cues. Review of Philosophy and Psychology 6 (4):591-610 Bengson Social Cues. Review of Philosophy and Psychology 6 (4).5 Intuitionism. Oxford University Press.

Boll-Avetisyan, N., Bhatara, A., \& Höhle, B. (2017). Effects of Musicality on the Perception of Rhythmic Structure in Speech. Laboratory Phonology: Journal of the Association for

Laboratory Phonology, 8(1), 9. DOI: http://doi.org/10.5334/labphon.91

Connolly, K. 2017 Perceptual Learning. The Stanford Encyclopedia of Philosophy (Summer 2017 Edition), Edward N. Zalta (ed.), URL =

<https://plato.stanford.edu/archives/sum2017/entries/perceptual-learning/>.

Connolly, K. 2019. Perceptual learning: The Flexibility of the Senses

Dreyfus, B.

Eberhardt, J. et al, 2004. Seeing Black: Race, crime, and visual processing.

Eilan, N., C. Hoerl, J. Roessler 2015. Joint attention: communication, and other minds. Oxford University Press.

Francis, G. 2016. "Implications of "Too Good to Be True" for Replication, Theoretical Claims, and Experimental Design: An Example Using Prominent Studies of Racial Bias." Frontiers in Psychology (7): 1382. Published online 2016 Sep 22.

Fridland, E. 2017. Motor skill and moral virtue. Royal Institute of Philosophy Supplement

80, 139-70. doi:10.1017/S1358246117000078

Goldstone, R. (2015) Perceptual Learning. In M. Matthen, ed. Oxford Handbook of the

Philosophy of Perception. Oxford University Press.

e: Harvard University Press.

Kant, I. Critique of Pure Reason.

Kelly, S. 2005.Seeng things in Merleau-Ponty.

. In W. Lycan, ed mind and Cognition. Blackwell. 29-57.

Mandelbaum, M. 1955. The Phenomenology of Moral Experience. Baltimore: Johns Hopkins Press.

Matherne, S. 2014. Kant and the art of schematism. Kantian Review. 19(2): 181-205 (2014) Matherne, S.2017 "Merleau-Ponty on Style as the Key to Perceptual Presence and

Constancy." Journal of the History of Philosophy 55(4): 693-727.

Merleau-Ponty, M. The phenomenology of perception. 6

McGrath. M. Knowing what things look like. Philosophical Review 126(1): 1-41.

${ }^{14}$ For more on these ideas, see Bengson (forthcoming), M. Mandelbaum (1955) Murdoch (1956)
Meissner, C.A., \& Brigham, J.C. (2001). Thirty years of investigating the own-race bias in memory for faces: A meta-analytic review. Psychology, Public Policy, and Law, 7, 3-35. Millar, A. 2019. Knowing by Perceiving. Oxford University Press.

Murdoch, I. 1956. "Vision and Choice in Morality" Aristotelian Society Supplementary Volume 30 (1):14-58.

Murdch, I. 1967. The Sovereignty of Good New York: Routledge.

Nanay, Bence (2015). Aesthetic attention. Journal of Consciousness Studies_ 22 (5-6):96-118. Noë, A. 2005. Action in Perception. Cambridge: MIT Press.

Noe, A. and K. O Regan 2001. A sensorimotor account of vision and visual consciousnessBehavioral and Brain Sciences 24

Pavese, C. 2015. Practical Senses. Philosophers' Imprint 15(29)

Pavese, C. (2019). The psychological reality of practical representation. Philosophical Pylyshyn (1999), Is Vision Con

n Continuous with Cognition? The Case for Cognitive Impenetrability (B) "Behavioral and Brain Sciences", 22, pp. 341-423. 